\title{
METHODS OF EXPERT ASSESSMENT OF SCIENTIFIC AND TECHNOLOGICAL TRENDS AND TECHNOLOGIES IN INTELLECTUAL NEURO-FUZZY SYSTEM
}

\author{
M. V. GRIBOVSKIY, S. V. GORBACHEV \\ and N. N. GORBACHEVA \\ National Research Tomsk State University \\ Lenina st., 36 \\ Tomsk \\ Russia \\ e-mail:mgrib@mail2000.ru \\ spp03@sibmail.com
}

\begin{abstract}
The article considers the problem of obtaining expert estimates and analysis of efficiency of scientific-technological areas and technologies, taking into account the professional identity of experts. Describes the capabilities of neuro-fuzzy analysis for the evaluation of innovation potential indicators of the 6-th technological structure. Provides a conceptual organization of an intelligent neuro-fuzzy system for prognosis and analysis.
\end{abstract}

\section{Introduction}

Assessment of the degree of efficiency of scientific-technological trends and technologies in the context of tough international competition is for the national economy urgently needed. From the depths of the

Keywords and phrases: technology, experts, professional identity, foresight, neuro-fuzzy analysis, forecast.

Received March 24, 2017

(C) 2017 Scientific Advances Publishers 
forecast in this area depends directly on the quality of taken managerial, infrastructural and investment decisions may have on the economy as a cumulative effect in the case of a correct forecast and to promote economic growth lockup due to wrong bets due to a failed forecast.

If the reality of the importance of adequate estimation of prospects of new technologies there is a question about instrumentation for this measurement. In the hands of the researcher to achieve this purpose can be a historical-genetic method, methods of marketing, statistical analysis. But a special place among the methods of evaluation of scientific and technological areas and technologies is the method of expert interviews.

The appeal to expert estimates, in this case, it is advisable in the following circumstances: as a result of the expert survey, the researcher expects to obtain from the expert a unique information, knowledge which is not readily available, as well as practical recommendations on scientific and technical policy. Appeal to the expert survey largely due to the difficulty of obtaining such information in any other way. To obtain correct results of processing of expert data is a topical issue of selection and application of mathematical methods of analysis.

The purpose of this study is the consideration of the peculiarities of obtaining expert assessments, taking into account the professional identity of experts and the capabilities of neuro-fuzzy analysis for the evaluation of innovation potential indicators of the 6-th technological structure.

\section{Features of Formation of the Expert Group}

A central aspect of the study depends on the correctness of the expected results is the formation of the expert group. Because of the importance of this aspect in recent years, the way to appear research covering the specifics of the formation of expert groups with regard to various surveys $[1,2,3]$. 
In relation to a range of respondents of the expert survey is qualitatively different from the mass opinion polls. If in the case of the last sample is based most often on a variety of demographic or personal characteristics of respondents (gender, age, place of residence, level of education, occupation, income level, etc.), when sampling in the expert survey the focus should be on competence of experts in the field to study the problems which they are involved.

Anyone in a professional relationship should be experts involved in assessing the effectiveness of scientific-technological areas and technologies? In our view, the appropriate sample for a survey is necessary to do of the four groups of experts:

- scientists/science administrators,

- representatives of innovative business,

- representatives of authorities,

- community representatives (leaders) of public organizations.

The emphasis in determining the pool of experts should be made on the first two groups in direct contact with new technologies.

An important detail which should be given attention, is the account of the factors influencing the judgment of an expert. Extras necessary to take into account emotional and psychological factors. Thus, the number of experts may be highly skilled professionals, potentially able to professionally judge the prospects for a particular technology, but as a person biased, it may deliberately overstate the prospects of development of the technology, which is connected with his professional activity, seeing it as a tool to improve their own (their lab, their production of) competitiveness. Related to this is the problem of correlation between "internal" and "external" experts. Generally, the research literature by "internal" experts refers to persons associated with the agency organising the examination [4]. However, in the case considered in the present work, the type of surveys suggest to consider "internal", not only employees of 
the institution which organised the study, but also experts, who are closely connected with the object of research (specific technology). Let's call them "internal" [inside the bar]. This allocation is necessary to have the possibility of considering the interest of the expert in answering a number of questions, with the understanding that "internal" experts are often well aware on many aspects of the problem being studied, which makes their participation in the study is highly desirable.

In this regard, it is promising and significant consideration of the range of potential experts involved in the analysis of efficiency of scientific-technological areas and technologies, through the prism of their professional identity.

Under the identity is commonly understood as a person's awareness of their belonging to different social, economic, national, professional, political, religious, racial and other communities [5]. Every person at the same time is a carrier of different identities and, as a rule, does not cause internal contradictions. However, possible conflict of identities. It is known that many innovative entrepreneurs have come out of the academic environment, and at times, becoming entrepreneurs, they do not leave a scientific career. The same can be said about the officials in charge of innovation.

When hiring a survey expert must take into account their potentially "double", "triple" identity. The interviewer should be aware of, as someone answers to his questions, the expert respondent. As a scientist and organizer of science? As a scientist or entrepreneur? As a scientist or bureaucrat? As an impartial professional or lobbyist to "their" technology?

This approach, taking into account the professional identity of experts was used in 2016 during the expert survey among scholars from British universities (Birmingham, Manchester Universities, Universities of Leeds and Sheffield). 
Involvement in expert work of the representatives of the authorities also has its own specifics, connected with the peculiarities of professional activity of officials [2].

Another important issue concerns the definition of the size of the group of experts. As you know, an expert survey, in contrast to the mass of opinion polls, does not require the participation of a large number of respondents. However, if the mass survey data reliability average rates is the higher, the more the totality of the respondents in the expert survey of the judgments of a small number of experts may be very valuable. This is due to the high competence of the participating entities.

Koshevoy et al. are inclined to the opinion on expediency of attraction to the survey from 10 to 30 experts [2]. Experience shows that wellknown outside of the increase in the number of experts does not give significant increase in new information either in detail or, more importantly, in quality. The need to limit the number of expert groups raises additional methodological requirements for the selection of experts, as it requires a reasonable combination of experts of different age, temperament, different scientific schools of affiliation. Based on the variety and diversity of innovative technologies, it seems appropriate to raise this figure up to $100-150$ experts.

Comparative analysis of methods for the selection of experts. And still remains unsolved important question: who should be these people? Who, exactly, to select experts in the analysis of efficiency of scientifictechnological areas and technologies? Attempts to answer this question is the subject of hundreds of special publications. Described in the literature methods for the selection of experts boil down to two basic approaches: objective and subjective. The first involves the study of special techniques of selection, the second - the involvement of the selection procedure potential experts or the scientific community, from which they are selected. 
The objective approach has, in turn, two ways: documentary and experimental. The first involves selection of experts based on sociodemographic data (academic degree, title, position, work experience a degree in a field related to the subject of the study, the number of published papers and number of citations in the scientific literature, participation in specialized councils, boards, symposia). The experimental method is based on testing, testing of candidate experts or the results of effectiveness of its previous expertise. Both of methodological technique require great sensitivity in relation to future expert. So, testing is not always acceptable from an ethical point of view. Yes, and the tests themselves still leave much to be desired. Verification of effectiveness of recommendations of the candidate in the experience of his previous work actually means an informal appraisal specialist. Therefore, both should be of a more auxiliary nature, be used in combination with the documentary approach and other methods.

The subjective approach also breaks down into several stages. One of them is the certification, when the selection of experts is carried out through open or secret ballot of prospective members of the future expert group, with the withdrawal of those who did not receive a certain minimum of votes. By itself, this technique is quite effective, but only if the members of the future groups know each other and have high scientific integrity. Otherwise there is a risk of challenge on a random, unprincipled motives, and therefore rely on just one this technique is impractical.

Another method of peer evaluation of future experts (in points or rankings) is essentially a variation of the first with all its features and limitations.

The third method is a method of self - assessment of the degree of competence and objectivity. Answering the questions, candidates assess their knowledge, erudition in the field of the research subject, the criticality of their assessment of a particular index (or indirect 
information, for example, the channels used information about the volume and nature of the study data, about their own contribution to the study of the problem being studied). In the future can be used to calculate average values of each candidate and the total sphere of competence of experts. Here, however, there is a risk of inadequacy of data in the form of inflated self-assessments.

Recent studies [6] allow to conclude that the more self-esteem the experts possess long professional experience as a factor of formation of professional identity. They are characterized by a higher level of reflection, differentiation of representations of self-identity. Subjects with less experience have less reflexivity, less adequate self-esteem, professional identity rather amorphous, professional image of the poorly differentiated, its definition is more commonly used job title.

Thus these methods and techniques have certain limitations, therefore, in our view, that the method of such selection should be based on a combination of various techniques.

One of the principles of formation of the expert group in this case may be the method of selection of the specified characteristics. For example, experts on the "quota" innovative business representatives must be selected, relevant to working effectively innovative industries. Scientists should be submitted to acknowledged experts in one of the most advanced technologies, etc. The obvious difficulty with this approach is that the selection of such experts must be the primary work of the expert group, is able to offer suitable candidates.

So, the main goal of the working group on the issue - improving the quality of evaluation of the effectiveness and feasibility of technical solutions and technologies. Expert judgment - in fact, the only effective way to make a prediction concerning the scientific and technical development. The most difficult task when preparing such expert survey is to develop a pool of experts, the method of such selection should be based on a combination of various techniques, including the specified 
characteristics. One of the important indicators for the selection of the expert group is professional experience as the factor of formation of professional identity. Experts with longer professional experience have higher level of reflection, differentiation of representations of selfidentity, and as a result, more self-esteem. In this case, you can use these other methods of self-evaluation on a certain scale. A very significant factor in the formation of the expert pool is the basis of professional identity of experts, ensuring correct perception of the expert judgments.

\section{The Method of "Technology of the Patent Surge"}

To define the characteristics of the 6-th technological mode [6] we take as the basis of the "technological blip" in a major foreign patent organizations and the Bureau.

Statement 1. The greater the concentration (amount) in the $\mathrm{X}$-direction, the higher the probability of formation of the industry (or technology) of the new 6-th technological order. This pattern is tested through a historical analysis of intellectual property major foreign patent offices, organizations and offices.

So, aware of the existence of technology that in the 1990s and 2000s changed the structure of the way, creating a new breakthrough in the industry. For example, consider the flow of intellectual property in the direction of cellular technologies in the dynamics. Build a model that will reveal the origins of technology-industries of the new technological order, using the "technological (patent) splash". This will give you the opportunity to confirm/add to the objectivity of the concept of Sergei Glazyev, refining industries of the 6-th technological structure. When the ratio of the model "technology (patent) of the burst" with historical data on implementation of this direction, it is possible to identify all the trends of the birth and emergence of the 6-th, 5-th, 4-th technological modes, and on this basis to develop all the necessary recommendations. 
Additional selection criterion technologies (industries) a new technological structure is the valuation of the technology.

Statement 2. The greater the gross value of the cluster of technologies in the direction (sector) $\mathrm{X}$, the higher the probability of forming a sector (or technologies) of the 6-th technological structure. So, we find another criterion for the study.

Thus, through the historical dynamics of intellectual property this technique allows to identify not only groundbreaking, but also "dying" industries and technologies.

\section{Intellectual Methods of Analysis and Forecast}

In our studies, we rely on the capabilities of neuro-fuzzy analysis for the evaluation of innovative potential of objects and areas. In recent years, much attention is paid to the development of intelligent systems combining fuzzy logic and neural networks. This is due to the fact that these two technologies complement each other, providing a synergistic effect [5].

Fuzzy neural networks are analogs of models of approximate reasoning, they have the ability to make the right decisions in conditions of incomplete and fuzzy information, to solve problems in which data, goals and constraints were too complex or poorly defined to allow precise mathematical analysis. At the same time, mathematical methods reflect fuzzy input data allow us to construct the neuro-fuzzy model, adequate to reality, which performs the intelligent processing of data and simultaneous detection of linguistic knowledge in the relevant areas of concern. In the general case, the disadvantage of these models is the a priori determination of them because of fuzzy statements, linguistic variables, fuzzy rule base structure, etc. For the parametric and structural identification of constructed models, we develop special methods based on neural network learning, cognitive modelling, decision trees, etc. 
In substructuring environment multi-criteria analysis of the appropriate joint to use these techniques to build an adequate system of analysis and forecast of scientific-technological development and decision support. This will extend opportunities to build intelligent systems with incomplete input information. The result is a hybrid neuro-fuzzy tools, which are characterized by strong cognitive capabilities (modelling, sensations, perceptions, recognition, learning and remembering patterns with the purpose of revealing of knowledge from data).

\section{Experimental Results}

The participants of the expert interviews and workshops were asked questions about indicators, which may be significant in the analysis of the transition to sixth wave of innovation and development model, aimed at the change in the wave of innovation. As a result, were identified the main groups and indicators (macroeconomic, research and development, geographical, climatic, historical, innovation). Major groups and indicators allowed us to monitor and assess the dynamics and trends in the formation of a new wave of innovation in the economy as part of the transition from the dominant technical structure to the next.

In addition, to build an adequate system of analysis and forecasting of techno-economic and scientific-technological development, the experts proposed to introduce in the group of investigated indicators the qualitative component of growth - productivity primary mass resources, which is measured as the ratio of gross domestic product and the economy cost of consumed primary resources mass [7]. Productivity as an indicator of the efficiency of resource use reflects the progress of the development of science and technology.

In order to improve the quality of the forecast is necessary to carry out simultaneous analysis of several available indicators (quantitative and qualitative analysis). Thus, to macroeconomic indicators, we added a qualitative component of economic growth, indicators of living standards, 
and - given the technological and innovative component - indicators of innovative activities.

The second stage expert interviews included the questions of the research of innovative technologies, including questions of their interaction from the point of view of influence on the process of conjugation and formation of the load-bearing sectors and clusters of economy of the new technological order. The results were processed by constructing neuro-fuzzy networks and fuzzy cognitive maps [8].

\section{Conceptual Organization of an Intelligent Neuro-Fuzzy System for Analysis and Forecast}

It should be noted that neural network models are highly configurable [9]. Initially, they include a set of quantitative and qualitative parameters described above. At subsequent stages of the model can be complemented with other characteristics on the basis of historical, cultural, psychological, climatic and other features of the country which determined in the course of expert studies [10]. Conceptual organization of an intelligent system includes two levels that are interconnected with analysis and forecast (Figure 1). This methodological approach fits and develops the methodology of the foresight research. 


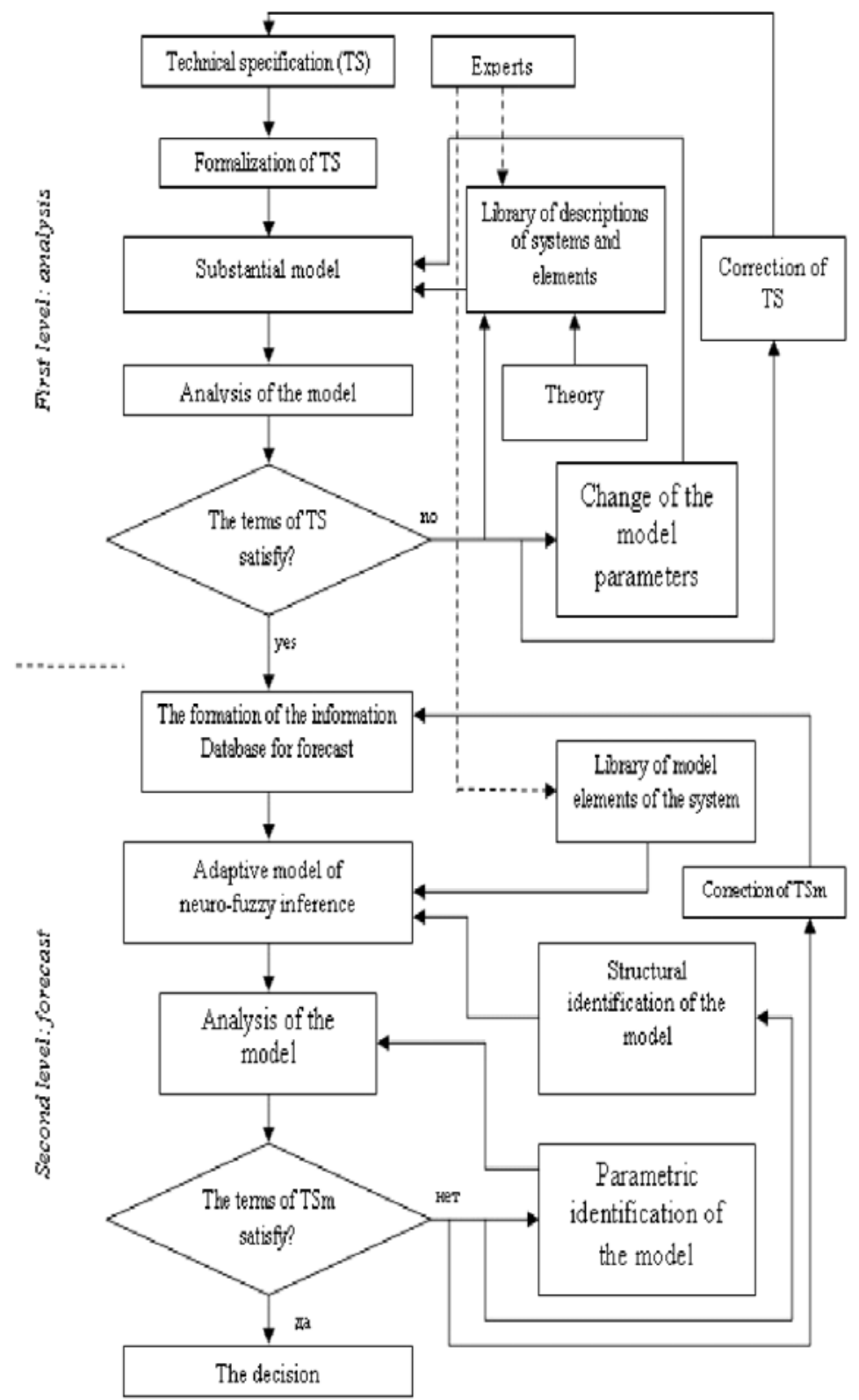

Figure 1. Conceptual organization of an intelligent neuro-fuzzy system for analysis and forecast. 


\section{Conclusion}

(1) On the basis of interdisciplinary studies the peculiarities of obtaining expert estimates in scientific-technological areas and technologies with the professional identity of experts.

(2) Developed a methodology of patent analysis based on historical and economic monitoring of documents with the aim of identifying "technological bursts".

(3) The efficiency of complex use of intellectual methods of analysis and forecast methods in the foresight study (multistage surveys, interviews, expert workshops).

(4) Developed and tested on the example of innovative technologies conceptual organization of an intelligent neuro-fuzzy system for the analysis and forecast of scientific-technological development of innovative objects and territories.

(5) The simulation results show that the choice of innovative scientific and technological areas requires consideration, taking into account the already achieved and potentially achievable level of development of national science and engineering compared with the world. The main objective of the new economic policy should be the creation of conditions in which the role of the "locomotive" of economic development will gradually move from raw materials and processing industries to innovative sector of the economy.

\section{Acknowledgement}

The research was performed under the program of competitiveness increase of National Research Tomsk State University the world's leading scientific and educational centers, with the financial support of Russian Foundation for Basic Research, Grant No. 16-29-12858. 


\section{References}

[1] O. V. Voronina and O. P. Sopina, Peculiarities of formation of the expert group in the examination of complex engineered systems, Proceedings of International scientificpractical conference "Psychology of labour, engineering psychology and ergonomics 2014" (Ergo 2014). Edited by A. N. Anokhin, P. I. Paderno and S. F. Sergeev, 2014, p. 452.

[2] O. S. Koshevoy, S. E. Golosov and Sh. G. Seidov, Organization of the expert survey with involvement of specialists of bodies of state and municipal management, News of Higher Educational Institutions, Povolzhskiy Region 1(21) (2012), 98-107.

[3] M. V. Sleptsova, Features of formation of the expert group for the assessment of the achieved learning outcomes in technology education, Modern Researches of Social Problems (Electronic Scientific Journal) 4 (48) (2015), 56-75.

[4] V. E. Shliapentoh, Problems of quality of sociological information: Validity, representativeness, predictive potential, M. (2006), 664 .

[5] V. S. Malakhov, The Identity, New philosophical encyclopedia, M.: Thought (2010), 78-79.

[6] M. A. Rensh and A. V. Lesik, Professional experience as a factor of formation of professional identity [electronic resource], Psychological Research: Electron. Scientific Sib. 3(17) (2011). URL: http://psystuduy.ru

[7] M. N. Uzyakov, Economic growth in Russia: Quantitative and qualitative components, Problems of Forecasting 3 (2004), 15-27.

[8] S. V. Gorbachev and N. N. Gorbacheva, Logically transparent neuro-fuzzy classifier for multi-criteria evaluation of efficiency of innovative development, Materials of VII international scientific-practical conference "REGIONAL PROBLEMS of transforming the ECONOMY: INTEGRATION PROCESSES AND SOCIOECONOMIC POLICY of the REGION", Makhachkala, 2016, p. 93-101.

[9] V. V. Kruglov, M. I. Dli and R. Y. Golunov, Fuzzy logic and artificial neural network: A training allowance, M.: Publishing House of Physico-mathematical Literature (2001), 224 .

[10] T. V. Abramov, S. V. Vaganova, S. V. Gorbachev, M. V. Gribovsky, V. I. Syryamkin, M. V. Syryamkin and T. V. Yakubovskaya, The cognitive system of monitoring and forecast of scientific-technological development of the state, Publishing House, Tomsk State University, Tomsk, 2012, p. 358. 